Original article

\title{
Metabolically healthy obesity: prevalence, phenotype characteristic, effectiveness of weight loss
}

\author{
Elena V. Ostrovskaya, Tatiana I. Romantsova, Andrei N. Gerasimov, Tamara E. Novoselova
}

I.M. Sechenov First Moscow State Medical University (Sechenov University), Moscow, Russia

Received 09 July 2020, Revised 13 August 2020, Accepted 24 August 2020

(C) 2020, Ostrovskaya E.V., Romantsova T.I., Gerasimov A.N., Novoselova T.E.

(C) 2020, Russian Open Medical Journal

Abstract: The goal was to study the prevalence of metabolically healthy obesity (MHO), the features of this phenotype compared with metabolically unhealthy obesity (MUHO), and the effect of weight loss on cardiometabolic risk factors in patients with MHO.

Material and Methods - To assess the prevalence of MHO, 389 case histories of obese patients aged 18-60 were analyzed. Three types of MHO criteria were used: 1) the definitions of metabolic syndrome (MS) according to International Diabetes Federation (IDF), 2005; 2) the HOMA-IR index (<2.7); 3) Biobank Standardisation and Harmonisation for Research Excellence in the European Union (BioSHaRE-EU) criteria, 2013. The study included comparative analysis of the medical history, anthropometry, basic metabolic parameters, and adipocytokine levels in 44 patients with MHO (taking into account the MS definitions) and 33 women with MUHO initially and with a decrease in body mass (BM) by $\geq 5 \%$ after 6 months.

Results - The MHO prevalence was: according to the definitions of MS - 38.6\%, according to HOMA-IR index - 34.5\%, in BioSHaRE-EU 9.6\%. All indicators of anthropometry, carbohydrate and lipid metabolism, including the HOMA-IR index, interleukin-6, and chemerin, as well as the duration of obesity in the MHO and MUHO groups significantly differed $(p<0.05)$. After 6 months, MHO-patients who lost $\geq 5 \%$ BM from the initial value (63.6\%) showed an increase of adiponectin, a decrease in waist circumference, HOMA-IR index, C-reactive protein (CRP), retinol-binding protein 4 (RBP-4), and chemerin $(p<0.05)$.

Conclusion - The MHO prevalence was maximal according to the MS definitions and minimal with BioSHaRE-EU criteria. The BM decrease in $\mathrm{MHO}$ is accompanied by a decrease in the content of proinflammatory adipocytokines and the HOMA-IR index, which determines the need to treat obesity regardless of the phenotype.

Keywords: metabolically healthy obesity, cardiometabolic risk, metabolic syndrome, insulin resistance, adipocytokines.

Cite as Ostrovskaya EV, Romantsova TI, Gerasimov AN, Novoselova TE. Metabolically healthy obesity: prevalence, phenotype characteristic, effectiveness of weight loss. Russian Open Medical Journal 2020; 9: e0301.

Correspondence to Elena V. Ostrovskaya. Phone: +79096265654. E-mail: e-ostrovsky@mail.ru.

\section{Introduction}

By 2016, more than 1.9 billion adults over the age of 18 were overweight ( $39 \%$ of men and $40 \%$ of women). Of these, more than 650 million were obese (about $13 \%$ of the world's adult population) [1]. Obesity is a major risk factor for Type 2 diabetes mellitus (Type 2 DM) and cardiovascular diseases (CVD). However, in a number of obese patients, the indicators of the lipid metabolism, blood pressure (BP), and carbohydrate metabolism remain unchanged. This phenotype is called metabolically healthy obesity (MHO) [2]. In most studies, the MS criteria serve as the starting point for defining $\mathrm{MHO}$ definitions. In this case, as a rule, the MHO group includes patients who have no more than 1 additional MS criterion besides obesity. In a number of other studies, the priority aspect is the normal insulin sensitivity of tissues [3].

In general, about 30 different definitions of MHO currently exist in clinical studies. The absence of a single standard of definitions determines the variability of data on the prevalence of this phenotype: it ranges from $6 \%$ to $60 \%$ [4]. In 2013, a group of European experts created the BioSHaRE-EU (Biobank Standardisation and Harmonisation for Research Excellence in
European Union) program to standardize biomedical research databases [5]. The first scientific development of the program was the MHO project: "Healthy Obesity Project". In this project, the metabolically healthy are obese patients (BMI of $30 \mathrm{~kg} / \mathrm{m}^{2}$ or more) who do not have any manifestations of MS according to the criteria of the Third national educational program on hypercholesterolemia (NCEP ATP III, USA). This study considers the nature of nutrition, physical activity, genetic features, the composition of the intestinal microflora, the structure of muscle tissue, etc. to be the potential determinants of metabolic health that determine the formation of this phenotype. Since the MHO phenotype is typical of less pronounced chronic smoldering inflammation, the study analyzes its contribution to the development of such factors as: adipocyte hypertrophy; an abundance of pro-inflammatory macrophages; excess visceral adipose tissue; ingestion of persistent organic pollutants that accumulate in adipose tissue, as well as the accumulation of chemicals related to plastic; metabolic endotoxemia caused by adverse intestinal microbiota (which in turn changes the level of endocannabinoids in the intestine and adipose tissue by regulating the levels of cannabinoid receptor agonists) [6]. Special attention 
is drawn to the study of the structure and function of adipose tissue. Currently, it is established that the amount of visceral adipose tissue in $\mathrm{MHO}$ is significantly less than in patients with complicated obesity. Patients with $\mathrm{MHO}$ and complicated obesity also showed significant differences in the gene expression profile and adipose tissue proteome [7]. Patients with MHO had a more favorable profile of circulating adipocytokines $[8,9]$. Currently, the issue of the need for treatment interventions aimed at reducing body mass in patients with $\mathrm{MHO}$ remains debatable: a significant number of authors cite data that a decrease in BM in $\mathrm{MHO}$ leads to an improvement in cardiometabolic risk indicators, body composition, and increased exercise tolerance [10, 11]. Other studies note that a significant reduction in cardiometabolic risk factors and an improvement in insulin sensitivity were not detected against the background of a decrease in BM [12].

The fact that, according to many researchers, MHO seems to be a temporary or transient phenotype and justifies treatment interventions to reduce $\mathrm{BM}$, despite the fact that positive changes in health status in this category of patients may be much more modest than in patients with complicated obesity [13].

The goal of this study was to determine the MHO prevalence considering various definitions and to study the main features of this phenotype (the content of adipocytokines in particular), as well as to assess the impact of weight loss on cardiometabolic risk factors in patients with $\mathrm{MHO}$.

\section{Material and Methods \\ Study design}

The first part of the work consists of a retrospective evaluation of 389 medical histories of patients aged 18 to 60 with obesity $\left(\mathrm{BMI} \geq 30 \mathrm{~kg} / \mathrm{m}^{2}\right.$ ) examined at the Department of Endocrinology of Sechenov University in 2003-2015. The sample included patients living in the Moscow region.

Three variants of criteria were used to identify the MHO phenotype:

1 - definitions of the IDF metabolic syndrome from 2005. In addition to the mandatory criterion - visceral obesity (waist circumference (WC) $\geq 94 \mathrm{~cm}$ for men and $\geq 80 \mathrm{~cm}$ for women) - the presence of no more than one of the following criteria: triglyceride (TG) level $\geq 150 \mathrm{mg} / \mathrm{dL}$ (1.69 mmol/L), or specific lipid lowering treatment; high-density lipoproteins (HDL) $<40 \mathrm{mg} / \mathrm{dL} \quad(1.0$ $\mathrm{mmol} / \mathrm{L})$ in men and $<50 \mathrm{mg} / \mathrm{dL}(1.3 \mathrm{mmol} / \mathrm{L})$ in women, or specific lipid lowering treatment; systolic blood pressure (SBP) $\geq 130 \mathrm{~mm}$ $\mathrm{Hg}$ or diastolic blood pressure (DBP) $\geq 85 \mathrm{~mm} \mathrm{Hg}$, or antihypertensive therapy; increased fasting plasma glucose (FPG) $\geq 110 \mathrm{mg} / \mathrm{dL}(5.6 \mathrm{mmol} / \mathrm{L})$

2 - definitions based on the HOMA-IR insulin resistance index. The $\mathrm{MHO}$ group included patients with HOMA-IR $<2.7$

3 - criteria BioSHaRE-EU of 2013. The metabolically healthy patients include obese patients who do not have any manifestations of MS according to the criteria of the Third National educational program on hypercholesterolemia (NCEP ATP III, USA), except for an WC increase in men more than $94 \mathrm{~cm}$, in women - more than $80 \mathrm{~cm}$ [5].

A further, more detailed analysis included metabolically healthy patients considering the MS criteria. The comparison group included patients with MUHO.
The study included comparative assessment of medical histories: patient complaints, age of onset of obesity, family history for overweight or obesity and cardiovascular diseases, previously used methods to reduce $\mathrm{BM}$, assessment of the structure of co-morbidities, the main indicators of anthropometry, the state of lipid and carbohydrate metabolism, and the functional state of the liver.

The second part of the work was an open prospective casecontrol study of 77 obese women aged 19-59 (BMI $\left.\geq 30 \mathrm{~kg} / \mathrm{m}^{2}\right)$. Of these, 44 were metabolically healthy, and 33 had metabolically unhealthy obesity: they were the control group. All patients filled out an informed consent form.

Initially and after 6 months, the patients were examined for anthropometry, carbohydrate and lipid metabolism, and adipocytokine levels against the background of weight loss.

\section{Eligibility criteria}

The eligibility criteria for the study were as follows: gender female, age 18 to 60 years for the retrospective sample and 19 to 59 years for the prospective group, and the presence of obesity $\left(\mathrm{BMI} \geq 30 \mathrm{~kg} / \mathrm{m}^{2}\right)$. The non-eligibility criteria were: gender - male, age under 18 and over 60 years, BMI less than $30 \mathrm{~kg} / \mathrm{m}^{2}$, the presence of chronic inflammatory and infectious diseases, Type 1 diabetes, severe form of Type 2 diabetes, chronic infectious and inflammatory diseases in the acute stage, severe somatic pathology, including myocardial infarction, stroke, cancer, pregnancy, and lactation.

\section{Study setting}

The study was conducted in the Endocrinology Clinic of the University Clinical Hospital No. 2 and the Department of Endocrinology No. 1 of the Faculty of Medicine of the Federal State Autonomous Educational Institution of Higher Education Sechenov First Moscow State University of the Ministry of Health of the Russian Federation (Sechenov University).

\section{Medical intervention}

In the prospective part of the study, all patients were given recommendations for lifestyle modification concerning nutrition and physical activity. Patients with multiple ineffective attempts to reduce body mass using diet therapy in their medical history were additionally prescribed pharmacotherapy for obesity (sibutramine, orlistat). The observation lasted for 6 months. The first and control examination after 6 months included evaluation of anthropometry data: initial height, body mass, WC, hip circumference (HC), BMI (calculated as the ratio of body mass $(\mathrm{kg})$ to the square of height $\left.\left(\mathrm{m}^{2}\right)\right)$, and indicators of carbohydrate and lipid metabolism, liver function, and adipocytokine levels. For 6 months, one of the two subgroups of patients underwent diet therapy in combination with recommendations for increasing physical activity; the other subgroup, in addition to lifestyle modification, received pharmacotherapy of obesity using various drugs: sibutramine (Reduxin), or orlistat (Xenical).

All biochemical and hormonal studies were carried out in the Interclinical Biochemical Laboratory of the Centralized Laboratory and Diagnostic Service of the Laboratory Blood Transfusion Complex of the Federal State Autonomous Educational Institution of Higher Education. I.M. Sechenov First Moscow State University 
of the Ministry of Health of the Russian Federation (Sechenov University).

The following biochemical parameters were determined from the morning portion of blood taken from the vein after an 8-hour fast: the lipid spectrum (total cholesterol, HDL, LDL, TG), alanine aminotransferase (ALT), aspartate aminotransferase (AST), glucose, C-peptide, and serum insulin. An indirect indicator of insulin resistance - the HOMA-IR index (Homeostasis Model Assesment - Insulin Resistance) was calculated using the formula fasting glucose $(\mathrm{mmol} / \mathrm{L}) \times$ fasting insulin $(\mathrm{u} / \mathrm{L}) / 22.5$. The HOMA-IR index $\geq 2.7$ was a criterion for the presence of insulin resistance.

Glucose, total cholesterol, HDL, LDL, TG, ALT, and AST parameters were determined using the Advia-1800 (Siemens) and Synchron CX5 and CX9 (Beckman Coulter) automatic biochemical analyzer. The level of insulin and C-peptide was measured using the Immulite 2000 (Siemens) analyzer.

High-sensitivity CRP (hs-CRP) was determined using an immunoturbidimetric method with an ADVIA 1200 biochemical analyzer with reference values of $0-5 \mathrm{mg} / \mathrm{L}$. The remaining cytokines were determined by enzyme immunoassay (EIA): TNF- $\alpha$ on the alpha-TNF-EIA-BEST test system produced by Vector-Best CJSC, reference values of $0-6 \mathrm{pg} / \mathrm{ml}$; adiponectin was tested on the Human Adiponectin ELISA test system produced by BioVendor Laboratorni medicina a.s., reference values for women average $13.2 \pm 6.1 \mathrm{ug} / \mathrm{ml}$; RBP-4 was tested on the Assaay test system max retinol-binding protein 4 (RBP-4) ELISA Kit manufactured by ASSAYPRO (average reference value-27.6 $\mathrm{ng} / \mathrm{ml}$ ). IL-6 was measured on the Human IL-6 Platinum ELISA test system produced by eBioscence, the average reference value in serum $0-12.7 \mathrm{pg} / \mathrm{ml}$; chemerin - on the Human Chemerin ELISA test system produced by BioVendor, reference values for women 3 to 19 years were $155.0-240.0 \mathrm{ng} / \mathrm{ml}, 20$ to 39 years: $140.0-245.0 \mathrm{ng} / \mathrm{ml}, 40$ to 59 years: $142.0-313.5 \mathrm{ng} / \mathrm{ml}, 60$ to 79 years: $170.0-452.2 \mathrm{ng} / \mathrm{ml}$.

Table 1. The structure of comorbidity and complaints in the MHO and MUHO groups (assessment of retrospective data)

\begin{tabular}{|c|c|c|c|c|}
\hline & Indicator & $\mathrm{MHO}, \%$ & MUHO, \% & $p$ \\
\hline \multirow{7}{*}{ 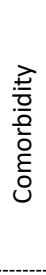 } & Dyslipidemia & 27.3 & 49.5 & $<0.05$ \\
\hline & Arterial hypertension & 25 & 71.5 & $<0.05$ \\
\hline & Steatohepatosis & 47.7 & 51.3 & $<0.05$ \\
\hline & Gynecological diseases & 50.8 & 61.4 & $<0.05$ \\
\hline & Allergic reactions & 42.2 & 38.3 & $<0.05$ \\
\hline & $\begin{array}{c}\text { Disorders of carbohydrate } \\
\text { metabolism }\end{array}$ & 6.8 & 39.1 & $<0.05$ \\
\hline & Diseases of the joints & 5.6 & 8.7 & $<0.05$ \\
\hline \multirow{9}{*}{ 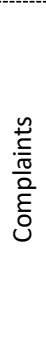 } & Dyspnea & 24.6 & 34.3 & $<0.05$ \\
\hline & Cardiac complaints & 9.7 & 21.3 & $<0.05$ \\
\hline & Fast fatiguability & 18.7 & 23.6 & 0.180 \\
\hline & General weakness & 15.7 & 22.7 & 0.083 \\
\hline & Menstrual irregularities & 11.9 & 14.4 & 0.284 \\
\hline & Back pain & 13.4 & 13.9 & 0.564 \\
\hline & Joint pain & 14.3 & 20.8 & 0.096 \\
\hline & Headaches & 9.0 & 13.4 & 0.122 \\
\hline & $\begin{array}{c}\text { Gastroenterological } \\
\text { complaints }\end{array}$ & 5.3 & 1.4 & 0.185 \\
\hline
\end{tabular}

MHO, metabolically healthy obesity; MUHO, metabolically unhealthy obesity; $p$, statistical significance of the frequency difference.

\section{Statistical analysis}

The data obtained in the study was processed using the IBM SPSS Statistics Version 22.0 for Windows statistical software package. Mean with statistical error of the mean value $(M \pm m)$, standard deviation $(\sigma)$, mediana (Me) and quartile values (with data presented in the form of lower and upper quartiles) were estimated. Due to the fact that some indicators had a distribution that was markedly different from the normal, and when analyzing the dynamics, groups of less than 30 patients were compared, a nonparametric criterion was used to assess the statistical significance of intergroup differences - the coefficient of rank correlation with the group number.

To compare frequencies, the $\chi$-square test in Fisher's exact solution was used. To evaluate the dynamics of numerical indicators, the change value was calculated as the difference $\Delta$ between the value during the last and first examination. To determine the reliability of the change, the average $\Delta$ value was compared with zero using the Student's criterion. The critical significance level for statistical hypothesis testing was assumed to be $p<0.05$. The sample size was not calculated beforehand.

\section{Results}

\section{Retrospective part of the study}

According to the analysis of 389 case histories of obese patients the prevalence of MHO by IDF, 2005 criteria was 38.6\%, the prevalence of $\mathrm{MHO}$ by HOMA-IR index was $34.5 \%$, the prevalence of $\mathrm{MHO}$ according to BioSHaRE-EU was $9.6 \%$.

When analyzing anamnestic data and complaints, it was found that, despite the status of being metabolically healthy, almost $90 \%$ of patients from the MHO group were worried about being overweight. In general, the differences in the frequency of complaints between the two study groups were statistically insignificant ( $p>0.05)$, except for dyspnea and cardiac complaints (Table 1). Smoking in the MHO group was three times less common than in the MUHO group. Analysis of the comorbidity structure in the groups of patients with $\mathrm{MHO}$ and MUHO showed that dyslipidemia, hypertension, steatohepatosis, gynecological diseases, allergic reactions and disorders of carbohydrate metabolism were statistically significantly more frequent in the MUHO group. The group of patients with $\mathrm{MUHO}$ compared with $\mathrm{MHO}$ used various methods of weight loss more often. For example, diet and physical activity were used by 39.4 and $24.1 \%$ of patients respectively, orlistat - by 4.3 and $1.2 \%$, various dietary supplements - by 2.9 and $1.2 \%$, sibutramine - by 1.2 and $1.7 \%$ respectively; 5.2 and $5.5 \%$ of the patients did not try to reduce weight.

This work analyzed the main anthropometric and laboratory indicators in patients with $\mathrm{MHO}$ and $\mathrm{MUHO}$. The average age of the study participants was $36.1 \pm 11.2$ years in the MHO group, and $42.2 \pm 11.2$ years in the MUHO group $(p<0.001)$. Comparison of the groups showed significant differences in all the studied indicators, except for height (Figure 1).

The average duration of obesity at the time of the survey in the $\mathrm{MHO}$ and $\mathrm{MUHO}$ groups was $18.7 \pm 12.3$ and $24.0 \pm 14.9$ years respectively $(p<0.001)$

Such indicators as age at the time of inclusion in the study, SBP, WC, fasting glucose, C-peptide, and TG were initially significantly lower in the MHO group $(p<0.05)$. The level of HDL in the $\mathrm{MHO}$ group was statistically significantly higher than in the patients with MUHO ( $p=0.018)$. 


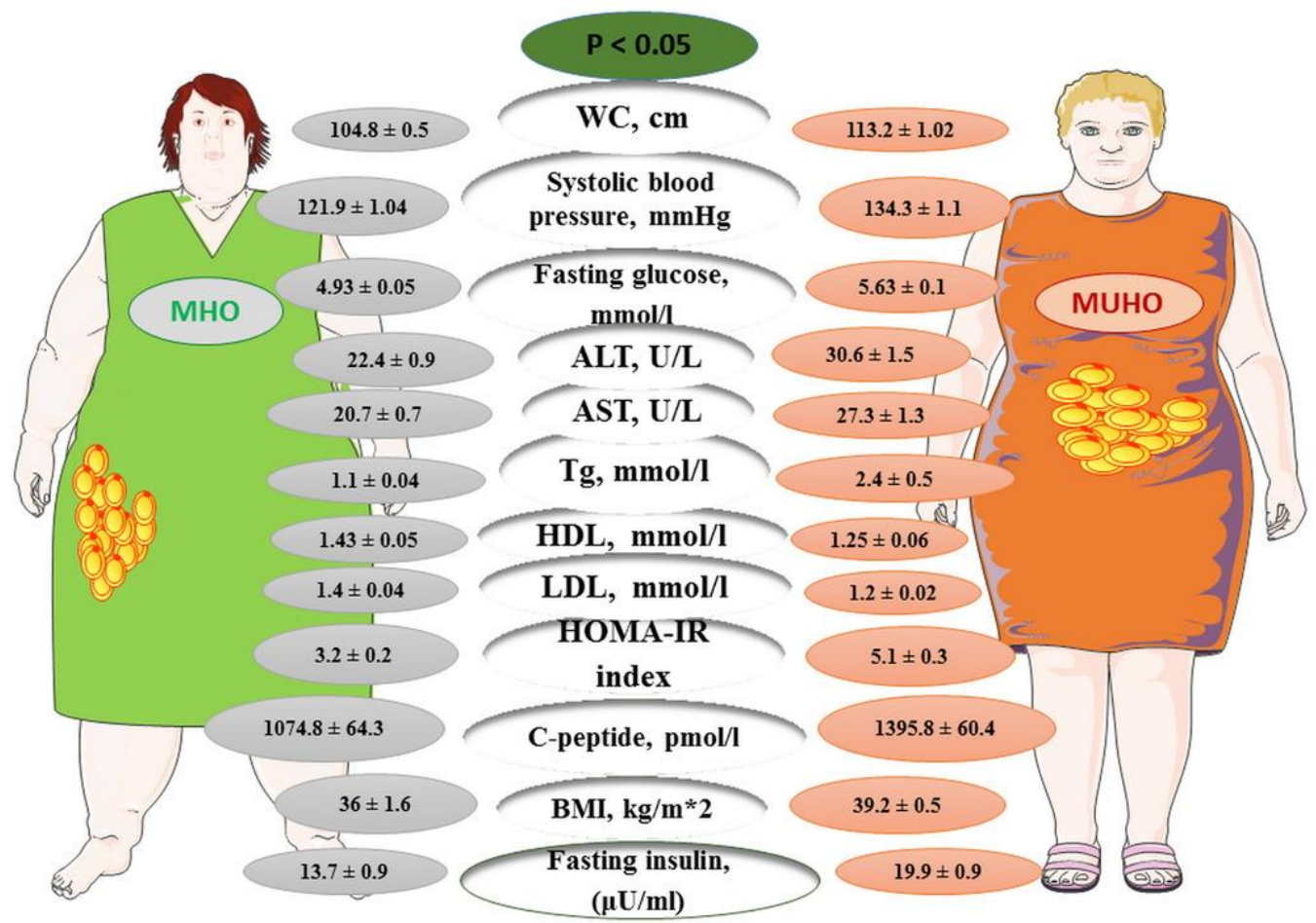

Figure 1. Comparative characteristics of the groups of patients with MHO and patients with MUHO (taking into account the criteria of IDF from 2005) (assessment of retrospective data).

$\mathrm{MHO}$, metabolically healthy obesity; MUHO, metabolically unhealthy obesity, indicators are shown in the format $\mathrm{M} \pm \mathrm{m}$, where $\mathrm{M}$ is the mean value, $\mathrm{m}$ is the statistical error of the mean value); WC, waist circumference; SBP, systolic blood pressure; ALT, alanineaminotransferase; AST, aspartaminotransferase; TG, triglycerides; HDL, high-density lipoproteins; LDL, low-density lipoproteins; BMI, body mass index.
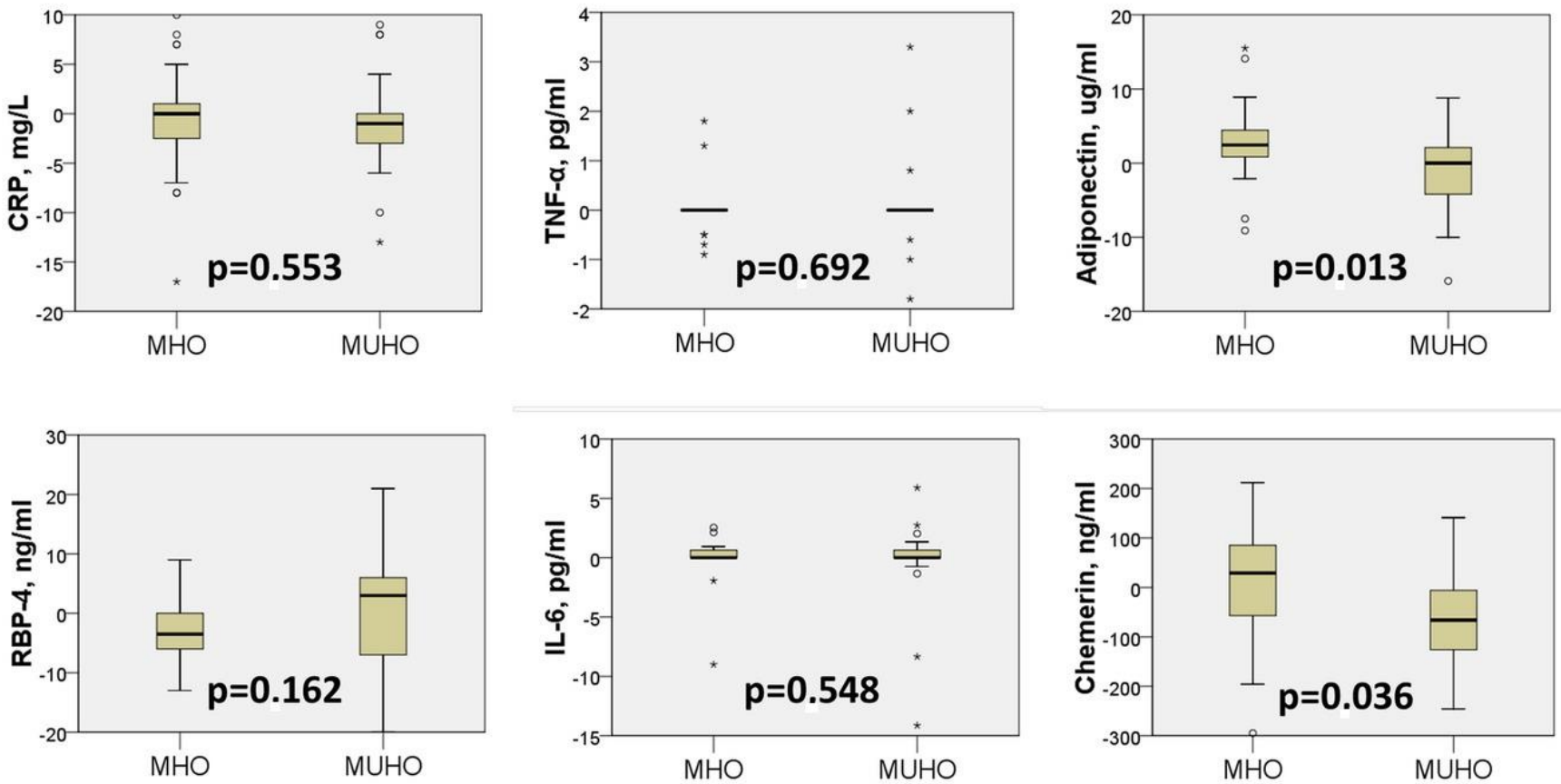

Figure 2. Dynamics of adipocytokine content against the background of clinically significant body mass decrease.

MHO, metabolically healthy obesity; MUHO, metabolically unhealthy (complicated) obesity; IL-6, interleukin-6; RPB-4, retinol-binding protein-4; CRP, Creactive protein; TNF- $\alpha$, tumor necrosis factor- $\alpha$; $p$ is a significant difference in mean ranks. 
Table 2. Comparative characteristics of patients in prospective group with MHO and MUHO initially (on the first visit before weight loss)

\begin{tabular}{|c|c|c|c|c|c|c|c|c|c|}
\hline \multirow{2}{*}{ Indicator } & \multicolumn{4}{|c|}{$\mathrm{MHO}(n=44)$} & \multicolumn{4}{|c|}{ MUHO (n=33) } & \multirow{2}{*}{$p$} \\
\hline & $\mathrm{M} \pm \mathrm{m}$ & $\sigma$ & $\mathrm{Me}$ & Quartiles & $\mathrm{M} \pm \mathrm{m}$ & $\sigma$ & $\mathrm{Me}$ & Quartiles & \\
\hline Height, $\mathrm{cm}$ & $166.41 \pm 0.71$ & 4.7 & 166.0 & $164 \div 168.75$ & $162.42 \pm 0.95$ & 5.5 & 162.0 & $159 \div 165.50$ & $<0.001$ \\
\hline Body mass, kg & $104.60 \pm 3.20$ & 21.1 & 99.0 & $87.85 \div 117.40$ & $102.50 \pm 2.50$ & 14.2 & 99.3 & $94.20 \div 110.70$ & 0.736 \\
\hline BMI, $\mathrm{kg} / \mathrm{m}^{2}$ & $37.89 \pm 1.18$ & 7.8 & 35.4 & $32 \div 40.75$ & $38.73 \pm 0.75$ & 4.3 & 39.0 & $35.50 \div 40.60$ & 0.083 \\
\hline $\mathrm{WC}, \mathrm{cm}$ & $106 \pm 2.20$ & 14.3 & 102.5 & $96.25 \div 117$ & $113 \pm 2.10$ & 12.1 & 112.0 & $106.30 \div 117.80$ & 0.016 \\
\hline $\mathrm{HC}, \mathrm{cm}$ & $125.20 \pm 2.10$ & 14.2 & 121.0 & $114 \div 135.50$ & $124.50 \pm 2.10$ & 11.8 & 122.0 & $119 \div 129$ & 0.907 \\
\hline $\mathrm{SBP}, \mathrm{mmHg}$ & $123.10 \pm 1.20$ & 8.2 & 120.0 & $120 \div 130$ & $130.50 \pm 2.50$ & 14.2 & 130.0 & $120 \div 140$ & 0.013 \\
\hline $\mathrm{DBP}, \mathrm{mmHg}$ & $78.90 \pm 1$ & 6.9 & 80.0 & $71.25 \div 80$ & $81.40 \pm 1.50$ & 8.9 & 80.0 & $80 \div 90$ & 0.110 \\
\hline Fasting glucose, $\mathrm{mmol} / \mathrm{L}$ & $5.04 \pm 0.07$ & 0.5 & 5.1 & $4.62 \div 5.30$ & $5.82 \pm 0.17$ & 1.0 & 5.6 & $5.19 \div 6.25$ & $<0.001$ \\
\hline ALT, U/L & $23.49 \pm 1.33$ & 8.8 & 20.9 & $17.70 \div 28.25$ & $37.39 \pm 4.47$ & 25.7 & 27.0 & $19 \div 55.50$ & 0.027 \\
\hline AST, U/L & $21.95 \pm 0.94$ & 6.2 & 22.0 & $18 \div 24$ & $27.79 \pm 2.88$ & 16.5 & 23.0 & $17 \div 32.50$ & 0.247 \\
\hline Total cholesterol, $\mathrm{mmol} / \mathrm{L}$ & $5.14 \pm 0.15$ & 1.0 & 5.1 & $4.52 \div 5.78$ & $5.73 \pm 0.19$ & 1.1 & 5.7 & $4.71 \div 6.67$ & 0.028 \\
\hline $\mathrm{TG}, \mathrm{mmol} / \mathrm{L}$ & $1.15 \pm 0.08$ & 0.5 & 1.1 & $0.78 \div 1.49$ & $1.94 \pm 0.17$ & 1.0 & 1.7 & $1.42 \div 2.27$ & $<0.001$ \\
\hline $\mathrm{HDL}, \mathrm{mmol} / \mathrm{L}$ & $1.43 \pm 0.05$ & 0.3 & 1.4 & $1.30 \div 1.55$ & $1.254 \pm 0.055$ & 0.3 & 1.2 & $1.04 \div 1.36$ & 0.002 \\
\hline $\mathrm{LDL}, \mathrm{mmol} / \mathrm{L}$ & $3.25 \pm 0.14$ & 1.0 & 3.2 & $2.77 \div 3.86$ & $3.89 \pm 0.18$ & 1.0 & 3.8 & $3.03 \div 4.61$ & 0.013 \\
\hline Fasting insulin, $\mu \mathrm{U} / \mathrm{ml}$ & $13.60 \pm 1.52$ & 10.1 & 11.2 & $6.95 \div 16.18$ & $17.14 \pm 1.93$ & 11.1 & 16.5 & $6.77 \div 23.6$ & 0.120 \\
\hline HOMA-IR index & $3.03 \pm 0.36$ & 2.4 & 2.6 & $1.49 \div 3.49$ & $4.43 \pm 0.56$ & 3.2 & 3.9 & $1.91 \div 5.45$ & 0.016 \\
\hline C-peptide, pmol/L & $1132 \pm 90$ & 573.0 & 998.0 & $755 \div 1320$ & $1503 \pm 96$ & 545.0 & 1424.0 & $1158 \div 1746$ & $<0.001$ \\
\hline hs-CRP, mg/L & $3.64 \pm 0.48$ & 3.2 & 2.0 & $1 \div 6$ & $4.55 \pm 0.84$ & 4.8 & 3.0 & $1.50 \div 5.50$ & 0.520 \\
\hline TNF- $\alpha, p g / m l$ & $0.54 \pm 0.03$ & 0.2 & 0.5 & $0.50 \div 0.50$ & $0.67 \pm 0.077$ & 0.4 & 0.5 & $0.50 \div 0.50$ & 0.099 \\
\hline Adiponectin, ug/ml & $11.11 \pm 0.82$ & 5.4 & 9.6 & $7.40 \div 15.18$ & $10.15 \pm 0.86$ & 5.0 & 9.4 & $6.55 \div 12.40$ & 0.540 \\
\hline $\mathrm{RBP}-4, \mathrm{ng} / \mathrm{ml}$ & $41.02 \pm 0.55$ & 3.7 & 41.0 & $38.25 \div 43$ & $41.15 \pm 0.72$ & 4.1 & 41.0 & $38.50 \div 45$ & 0.489 \\
\hline $\mathrm{IL}-6, \mathrm{pg} / \mathrm{ml}$ & $0.76 \pm 0.16$ & 1.1 & 0.5 & $0.46 \div 0.46$ & $1.85 \pm 0.580$ & 3.3 & 0.5 & $0.46 \div 1.50$ & 0.035 \\
\hline Chemerin, $\mathrm{ng} / \mathrm{ml}$ & $320.10 \pm 14.50$ & 96.4 & 312.5 & $242.50 \div 368.30$ & $369.2 \pm 19.70$ & 113.3 & 356.0 & $302 \div 414.50$ & 0.032 \\
\hline Age, years & $35.80 \pm 1.33$ & 8.8 & 34.0 & $29 \div 40.75$ & $42.55 \pm 2.05$ & 11.8 & 43.0 & $31.50 \div 53$ & 0.009 \\
\hline Duration of obesity, years & $17.91 \pm 1.53$ & 10.2 & 18.5 & $9 \div 26.75$ & $22.58 \pm 2.60$ & 15.0 & 20.0 & $11 \div 28$ & 0.269 \\
\hline
\end{tabular}

$\mathrm{M}$, mean value; $m$, statistical error of the mean value; $n$, number of patients; $p$, statistical significance of mean difference, variance analysis; Me, median.

Table 3. The difference in the studied indicators in the MHO and MUHO groups in patients after $\geq 5 \%$ weight loss over 6 months

\begin{tabular}{|c|c|c|c|c|c|}
\hline \multirow{2}{*}{ Показатель $\Delta$} & \multicolumn{2}{|c|}{$M 30(n=28)$} & \multicolumn{2}{|c|}{$M H O(n=21)$} & \multirow{2}{*}{$p$} \\
\hline & $\mathrm{M} \pm \mathrm{m}$ & $\mathrm{p}_{1}$ & $\mathrm{M} \pm \mathrm{m}$ & $\mathrm{p}_{2}$ & \\
\hline WC, $\mathrm{cm}$ & $-8.55 \pm 1.00$ & $<0.001$ & $-9.82 \pm 1.12$ & $<0.001$ & 0.453 \\
\hline $\mathrm{HC}, \mathrm{cm}$ & $-7.66 \pm 0.90$ & $<0.001$ & $-7.68 \pm 0.93$ & $<0.001$ & 0.943 \\
\hline $\mathrm{SBP}, \mathrm{mmHg}$ & $-4.38 \pm 1.53$ & 0.010 & $-9.09 \pm 5.05$ & 0.090 & 0.431 \\
\hline $\mathrm{DBP}, \mathrm{mmHg}$ & $-1.03 \pm 1.25$ & 0.420 & $-1.59 \pm 2.67$ & 0.560 & 0.589 \\
\hline Fasting glucose, $\mathrm{mmol} / \mathrm{L}$ & $-0.05 \pm 0.16$ & 0.770 & $-0.49 \pm 0.23$ & 0.050 & 0.094 \\
\hline AST, U/L & $-1.78 \pm 1.45$ & 0.230 & $-4.12 \pm 2.35$ & 0.110 & 0.935 \\
\hline Total cholesterol, $\mathrm{mmol} / \mathrm{L}$ & $-0.03 \pm 0.20$ & 0.890 & $-0.57 \pm 0.23$ & 0.020 & 0.157 \\
\hline $\mathrm{TG}, \mathrm{mmol} / \mathrm{L}$ & $0.18 \pm 0.19$ & 0.330 & $-0.32 \pm 0.25$ & 0.230 & 0.021 \\
\hline $\mathrm{HDL}, \mathrm{mmol} / \mathrm{L}$ & $0.07 \pm 0.05$ & 0.220 & $0.01 \pm 0.06$ & 0.910 & 0.806 \\
\hline $\mathrm{LDL}, \mathrm{mmol} / \mathrm{L}$ & $-0.23 \pm 0.19$ & 0.240 & $-0.76 \pm 0.21$ & $<0.001$ & 0.120 \\
\hline Fasting insulin, $\mu \mathrm{U} / \mathrm{ml}$ & $-5.17 \pm 2.52$ & 0.012 & $-3.39 \pm 2.62$ & 0.210 & 0.573 \\
\hline HOMA-IR index & $-1.13 \pm 0.55$ & 0.016 & $-1.21 \pm 0.77$ & 0.130 & 0.266 \\
\hline C-peptide, pmol/L & $-183.29 \pm 124.89$ & 0.150 & $-96.46 \pm 160.23$ & 0.560 & 0.771 \\
\hline $\mathrm{TNF}-\alpha, \mathrm{pg} / \mathrm{ml}$ & $-0.11 \pm 0.14$ & 0.440 & $-0.03 \pm 0.14$ & 0.850 & 0.835 \\
\hline Adiponectin, ug/ml & $4.55 \pm 0.83$ & $<0.001$ & $1.97 \pm 0.81$ & 0.020 & 0.018 \\
\hline $\mathrm{RBP}-4, \mathrm{ng} / \mathrm{ml}$ & $-2.97 \pm 1.00$ & 0.010 & $0.19 \pm 2.01$ & 0.790 & 0.133 \\
\hline $\mathrm{IL}-6, \mathrm{pg} / \mathrm{ml}$ & $-0.14 \pm 0.14$ & 0.320 & $-1.56 \pm 0.74$ & 0.060 & 0.531 \\
\hline Chemerin, $\mathrm{ng} / \mathrm{ml}$ & $-45.68 \pm 17.06$ & 0.010 & $-59.57 \pm 20.39$ & $<0.001$ & 0.048 \\
\hline
\end{tabular}

$\mathrm{M}$, mean value of the ratio; $\mathrm{m}$, statistical error of the mean value; $\Delta$, dynamics of each indicator at the third examination (the difference between the value at the third examination and the initial value); $p$, statistical significance of differences between the mean value of $\Delta$ from zero; $n$, number of patients.

\section{Prospective part of the study}

In the prospective part of the study, the initial characteristics of the studied groups are presented in Table 2.

Initially, neither the mean values nor the distributions of BMI, fasting insulin, hs-CRP, TNF- $\alpha$, adiponectin, and RBP-4 were statistically significantly different in the two groups. Statistically significant differences in the MHO and MUHO groups were observed in the indicators of the HOMA-IR index $-3,03 \pm 0,36$ and

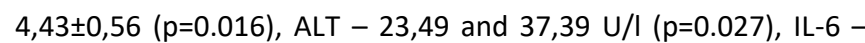
$0,76 \pm 0,16$ and $1,85 \pm 0,58 \mathrm{pg} / \mathrm{ml}(\mathrm{p}=0.035)$, chemerin $-320,1 \pm 14,5$ and $369,2 \pm 19,7 \mathrm{ng} / \mathrm{ml}(\mathrm{p}=0.032)$, age at the beginning of the study $-35,80 \pm 1,33$ and $42,55 \pm 2,05$ years $(p=0.009)$. After 6 months in the $\mathrm{MHO}$ group, a decrease in $\mathrm{BM}$ by $5 \%$ or more was observed in 28 people $(63.6 \%)$, in the MUHO group - in 21 patients $(63.6 \%)$. The difference between the studied indicators: the outcome and dynamics $(\Delta)$ are shown in Table 3. 
In Table 3, p1 and p2 are the reliability of the difference between the mean value of the change from zero in the two groups, $p$ is the reliability of the differences when comparing the first and second groups. Due to the small size of the groups, the values of $\mathrm{p} 1$ and $\mathrm{p} 2$ are indicative.

At the same time, when comparing the values in the MLO and INR groups in Tables 2 and 3, the analysis of rank correlations of indicators with the group number is used, that is, an exact nonparametric criterion, the correctness of which does not depend on the nature of the distributions of the studied values or on the number of observations.

The MHO group showed a statistically significant $(p<0.05)$ decrease in BMI, WC, HC, SBP, fasting insulin, HOMA-IR index, hsCRP, RBP-4, and chemerin, as well as a statistically significant increase in adiponectin levels against the background of a decrease in $\mathrm{BM}$ by $\geq 5 \%$. The MUHO group showed a statistically significant decrease in $\mathrm{BMI}, \mathrm{WC}, \mathrm{HC}$, fasting glucose, total cholesterol, LDL, hs-CRP and chemerin (for IL-6 p=0,060), as well as a statistically significant increase in adiponectin levels against a decrease in $\mathrm{BM}$ by $\geq 5 \%$. All patients who received various medications for the treatment of obesity (sibutramine: $n=8$, orlistat: $n=5$ ) were grouped into a single subgroup "Lifestyle modification + pharmacotherapy", hereinafter "Pharmacotherapy" $(n=13)$. There were no statistically significant differences in changes in BM, WC and $\mathrm{HC}$ indicators at the second examination in the subgroups "Lifestyle modification" and "Pharmacotherapy (sibutramine, orlistat)" in either the MHO or the MUHO group.

When comparing the dynamics of the studied indicators in the $\mathrm{MHO}$ and MUHO groups, the statistically significant differences were found in the level of TG $(+0.18 \pm 0.19 \mathrm{mmol} / \mathrm{L}$ vs $-0.32 \pm 0.25$ $\mathrm{mmol} / \mathrm{L}, \mathrm{p}=0,021)$, adiponectin $(+4.55 \pm 0.83 \mathrm{ug} / \mathrm{ml} \mathrm{vs}+1.97 \pm 0.81$ $\mathrm{ug} / \mathrm{ml}, \mathrm{p}=0.018)$, chemerin $(-45,68 \pm 17,06 \mathrm{ng} / \mathrm{ml}$ vs $-59,57 \pm 20,39$ $\mathrm{ng} / \mathrm{ml}, \mathrm{p}=0,048$ ) respectively (Figure 2 ). There were no statistically significant differences in WC, fasting glucose, fasting insulin, HDL, HOMA-IR index, hs-CRP, TNF- $\alpha$, RBP-4 and chemerin.

Using the Spearman's rank correlation coefficient in the group of patients with MUHO, we noted a positive correlation between a decrease in hs-CRP level and a decrease in C-peptide level $(r=0.446, p<0.05)$, a negative correlation between a decrease in TNF- $\alpha$ and age $(r=-0.541, p<0.01)$, negative correlation between the dynamics of the level of chemerin and BMI $(p<0.01, r=-0.567)$, the dynamics of the level of chemerin and OT $(p<0.05, r=0.5)$, positive - between the dynamics of the level of chemerin and TG $(p<0.05, r=0.43)$. In the MHO and MUHO group, there was a positive correlation between a decrease in IL- 6 levels and an increase in $\mathrm{HDL}$ cholesterol $(r=0.417, p<0.05)$, a positive correlation between the dynamics of RBP-4 and WC ( $r=0.427$, $p<0.05$ ). At the same time in the MUHO group there was a positive correlation between a decrease in the level of RBP-4 and a decrease in the level of insulin and the HOMA-IR index ( $r=0.459$, $\mathrm{p}<0.05)$.

\section{Undesirable effects}

No undesirable effects were observed in the course of the study.

\section{Discussion}

The results of the National Health and Nutrition Examination Surveys (NHANES, USA) are an example of a clear relationship between the prevalence of $\mathrm{MHO}$ and its definitions. Among the 5440 participants, $31.7 \%$ of obese patients were considered to be metabolically healthy taking into account the presence of no more than one of the 6 cardiometabolic risk factors like increased blood pressure, TG levels, fasting glycemia, hs-CRP, reduced HDL, and insulin sensitivity. The stricter criteria assume the absence of all 6 factors: only $16.6 \%$ of obese patients were referred to the MHO group. In the same sample, changes in the threshold values of the HOMA-IR index from 5.1 to 2.5 led to a reduction in the number of MHO patients up to $6 \%$ [14]. The greatest prevalence of the MHO phenotype was stated taking into account the use of MS criteria according to IDF from 2005: 38.6\%. A group of Russian authors (O. Rotar et al.) studied the MHO prevalence in 13 regions of Russia (Volgograd, Vologda, Voronezh, Vladivostok, Ivanovo, Kemerovo, Krasnoyarsk, Orenburg, Tomsk, Tyumen, Saint Petersburg and North Ossetia-Alania) with the participation of 1,600 people aged 25 to 65 . The maximum MHO prevalence with the criteria of MS according to IDF was noted in Tyumen: it was $52.2 \%$. The minimum was recorded in Voronezh: $25.7 \%$, with a total prevalence of $41 \%$ and no significant gender differences [15]. In another Russian study of the researchers from Saint Petersburg, the MHO prevalence was significantly lower - only $8.7 \%$ [16]. The lower indicators were predetermined by the fact that in this study, the $\mathrm{MHO}$ criteria included a combination of the minimum number of manifestations of the metabolic syndrome in combination with normal tissue sensitivity to insulin.

The absence of a statistically significant difference in the frequency of complaints in the MHO and MUHO group allows concluding that there is some discrepancy between the concept of $\mathrm{MHO}$ in terms of the used anthropometric and laboratory criteria and the subjective feelings of the patient.

In this work, the special attention was drawn to the study of the level of adipocytokines. Adiponectin is an adipokine synthesized exclusively in adipose tissue. It has a distinct antidiabetogenic, anti-atherogenic, and anti-inflammatory effect. Adiponectin inhibits phagocytic activity and production of IL-6 and TNF- $\alpha$ by macrophages, and can also induce the formation of antiinflammatory cytokines $\mathrm{IL}-10$ and $\mathrm{IL}-1$ by monocytes and macrophages [17]. Initially, the level of adiponectin did not differ significantly in the MHO and MUHO groups, which can be explained by a comparable BMI in these patients. Besides, against the background of a decrease in BM by $\geq 5 \%$ in both groups the increase in adiponectin level was statistically significant $(p<0.05)$ and in the MHO group significantly higher than in the case of complicated obesity, which indicates the feasibility of reducing BM in all obese patients, regardless of the phenotype.

C-reactive protein (CRP) is synthesized mainly in the liver under the stimulating influence of IL- 6 and TNF- $\alpha$, as well as in adipose tissue. By stimulating the expression of adhesion molecules ICAM-1, VCAM-1 and E-selectin on the endothelial surface (which leads to binding and modification of very lowdensity lipoprotein cholesterol (VLDL)), CRP initiates chronic vascular inflammation and atherogenesis. One of the most important independent factors in the development of coronary heart disease is an increase in the level of CRP in blood plasma [18]. Despite the absence of a statistically significant difference in the level of CRP in the MHO and MUHO groups initially, after a BM 
decrease by $\geq 5 \%$, the CRP level significantly decreased in both groups.

Tumor necrosis factor- $\alpha$ (TNF- $\alpha$ ) is a proinflammatory cytokine synthesized in monocytes and macrophages. It plays a major role in the development of inflammation and autoimmune diseases along with IL-6 [19]. The expression of TNF- $\alpha$ in human adipose tissue is relatively small, and it decreases as the BM decreases. An experiment on several independent animal models has indicated that treatment with anti-TNF- $\alpha$ antibodies reduces the severity of inflammation, fatty liver disease, and insulin resistance [20]. For TNF- $\alpha$, there were no statistically significant differences between $\mathrm{MHO}$ and MUHO both initially and after a decrease in BM by $\geq 5 \%$ in each of these groups. A similar result was obtained in the work of L.M. Berstein and co-authors (2017) [21].

IL- 6 can induce the synthesis of pro-inflammatory proteins in the liver like fibrinogen and CRP. Under the influence of IL- 6 , the expression of lipoprotein lipase in adipocytes decreases, and their absorption of free fatty acids increases; in turn, it leads to an increase in TG production. Plasma IL-6 levels negatively correlate with insulin sensitivity [18]. In terms of this study, the higher levels of IL-6 were initially observed in the MUHO group. On the background of weight loss in 6 months $\geq 5 \%$, the MUHO group showed statistically significant reduction in the level of IL-6, if compared to initial values and compared with the $\mathrm{MHO}$ group.

Retinol-binding protein 4 (RBP-4) is secreted in adipocytes and hepatocytes and transports retinol from the liver to various tissues. Many studies have shown a relationship between the level of RBP-4 and arterial hypertension, hypertriglyceridemia and a decrease in HDL. RBP-4 disrupts the action of insulin in the muscles by reducing tyrosine phosphorylation in the receptor [17]. Apparently, the absence of a statistically significant difference in the level of RBP-4, one of the cytokines maximum related to the development of insulin resistance, in the $\mathrm{MHO}$ and MUHO groups is partly due to the mean value of the HOMA-IR index in both groups $>2.7$. After a $\mathrm{BM}$ decrease by $\geq 5 \%$ in the $\mathrm{MHO}$ group, the decrease in the level of RBP-4 was statistically significant $(p<0.05)$ in contrast to the MUHO group $(p=0.79)$, which indicates the feasibility of reducing MT in metabolically healthy patients.

One of the interesting and ambiguous adipokines, chemerin is mainly secreted by adipocytes, preadipocytes and cells of the vascular-stromal fraction of adipose tissue and is a chemoattractant for various types of immune cells. It can contribute to both the emergence of immune responses (according to most authors) and the resolution of inflammation, depending on the isomeric form. There is an indication of the antitumor effect of chemerin in the lungs, skin, reproductive system, and digestive tract [22]. According to the obtained data, the $\mathrm{MHO}$ group initially had significantly lower level of chemerin than that of MUHO group. After the $\geq 5 \%$ decrease in BM, the level of chemerin statistically significantly decreased in each group of patients with a statistically significant difference between groups.

When using the IDF criteria (2005) for referring patients to the MHO or MUHO group, the HOMA-IR index indicators corresponding to the presence of insulin resistance in both groups were found with a statistically significant difference $(p=0.031)$ between them. It correlates with data from other authors who had used the same definitions of MHO [23]. This once again indicates the need to optimize and unify the criteria for MHO.

\section{Conclusion}

Thus, the maximum prevalence of $\mathrm{MHO}$ is observed when using the MS criteria (38.6\%), the minimum - when using the BioSHaRE-EU criteria (9.6\%). Due to the large variability of data on prevalence depending on the accepted criteria, it is necessary to develop common definitions of the MHO. The main indicators of anamnestic data, carbohydrate, lipid metabolism, anthropometry were statistically significantly different in the studied groups of patients. The longer existence of obesity in the MUHO group suggests that $\mathrm{MHO}$ is a potentially unstable phenotype and, may transform into a metabolically unhealthy one over time. A clinically significant decrease in body weight in patients with $\mathrm{MHO}$ compared to MUHO is accompanied by a slightly more pronounced decrease in insulin resistance and levels of a number of pro-inflammatory adipokines with an increase in the antiinflammatory adipokine - adiponectin. This determines the need to treat obesity regardless of the phenotype.

\section{Limitations}

The study's limitations include a relatively small sample of patients receiving pharmacotherapy for obesity.

\section{Conflict of interest}

Some results of this study was presented on 3rd International Conferences on Obesity and Chronic Diseases (July 23-25, 2018, Los Angeles, United States), published as abstract in the collection of abstracts of the Conferences https://obesity.unitedscientificgroup.org/pdfs/ICOCD Book-2018.pdf (p. 48), and published in Almanac of Clinical Medicine: Adipocytokine profile and effectiveness of the weight loss in patients with metabolically healthy obesity. 2018; 46(3): 212-221, https://doi.org/10.18786/2072-0505-201846-3-212-221.

The authors declare no obvious or potential conflict of interest related to the publication of the present article.

\section{Ethical approval}

The clinical study within the framework of the dissertation (thesis) was approved by the Interuniversity Ethics Committee under the Association of Russian Medical Pharmaceutical Universities (Minutes No. 10 of a meeting of the Interuniversity Ethics Committee under the Association of Russian Pharmaceutical Universities from 17 Nov, 2011).

\section{References}

1. WHO Media Centre. Fact Sheet: Obesity and overweight 1 April 2020. https://www.who.int/news-room/fact-sheets/detail/obesity-andoverweight.

2. Alam I, Ng T, Larbi A. Does inflammation determine whether obesity is metabolically healthy or unhealthy? The aging perspective. Mediators Inflamm 2012; 2012: 456456. https://doi.org/10.1155/2012/456456.

3. Schulze MB. Metabolic health in normal-weight and obese individuals. Diabetologia 2019; 62(4): 558-566. https://doi.org/10.1007/s00125018-4787-8.

4. Smith GI, Mittendorfer B, Klein S. Metabolically healthy obesity: facts and fantasies. J Clin Invest 2019; 129(10): 3978-3989. https://doi.org/10.1172/jci129186.

5. van Vliet-Ostaptchouk JV, Nuotio ML, Slagter SN, Doiron D, Fischer K, Foco $L$, et al. The prevalence of metabolic syndrome and metabolically healthy obesity in Europe: a collaborative analysis of ten large cohort studies. BMC Endocr Disord 2014; 14: 9. https://doi.org/10.1186/14726823-14-9. 
6. Brandão I, Martins MJ, Monteiro R. Metabolically Healthy Obesity Heterogeneity in Definitions and Unconventional Factors. Metabolites 2020; 10(2): 48. https://doi.org/10.3390/metabo10020048.

7. Alfadda AA., Masood A, Al-Naami MY, Chaurand P, Benabdelkamel $\mathrm{H}$. A proteomics based approach reveals differential regulation of visceral adipose tissue proteins between metabolically healthy and unhealthy obese patients. Mol Cells 2017; 40(9): 685-695. https://doi.org/10.14348/molcells.2017.0073.

8. Khan UI, Ogorodnikova AD, Xu L, Wang D, Wassertheil-Smoller S, Ho $\mathrm{GY}$, et al. The adipokine profile of metabolically benign obese and atrisk normal weight postmenopausal women: the Women's Health Initiative Observational Study. Obesity (Silver Spring) 2014; 22(3): 786794. https://doi.org/10.1002/oby.20139.

9. Antoniades C. 'Dysfunctional' adipose tissue in cardiovascular disease: a reprogrammable target or an innocent bystander? Cardiovasc Res 2017; 113(9): 997-998. https://doi.org/10.1093/cvr/cvx116.

10. Palau-Rodriguez $M$, Garcia-Aloy $M$, Miñarro $A$, Bernal-Lopez $M R$, Brunius C, Gómez-Huelgas R, et al. Effects of a long-term lifestyle intervention on metabolically healthy women with obesity: Metabolite profiles according to weight loss response. Clin Nutr 2020; 39(1): 215224. https://doi.org/10.1016/j.clnu.2019.01.018.

11. Dalzill C, Nigam A, Juneau $M$, Guilbeault $V$, Latour $E$, Mauriège $P$, et al. Intensive lifestyle intervention improves cardiometabolic and exercise parameters in metabolically healthy obese and metabolically unhealthy obese individuals. Can J Cardiol 2014; 30(4): 434-440. https://doi.org/10.1016/j.cjca.2013.11.033.

12. Kantartzis K, Machann J, Schick F, Rittig K, Machicao F, Fritschee A, et al. Effects of a lifestyle intervention in metabolically benign and malign obesity. Diabetologia 2011; 54(4): 864-868. https://doi.org/10.1007/s00125-010-2006-3.

13. Blüher M. Metabolically Healthy Obesity. Endocr Rev 2020; 41(3): 405420. https://doi.org/10.1210/endrev/bnaa004.

14. Wildman RP, Muntner P, Reynolds K, McGinn AP, Rajpathak S, WylieRosett J, et al. The obese without cardiometabolic risk factor clustering and the normal weight with cardiometabolic risk factor clustering: prevalence and correlates of 2 phenotypes among the US population (NHANES 1999-2004). Arch Intern Med 2008; 168(15): 1617-1624. https://doi.org/10.1001/archinte.168.15.1617.

15. Rotar O, Konradi A, Shalnova S, Balanova, Y, Deev A, Oschepkova E, et al. Metabolically healthy obesity and metabolically obese normal weight in Russian population. Journal of hypertension 2016; 34: e16. https://doi.org/10.1097/01.hih.0000491368.63715.51.

16. Berezina A, Belyaeva O, Berkovich O, Baranova E, Karonova $T$, Bazhenova $E$, et al. Prevalence, risk factors, and genetic traits in metabolically healthy and unhealthy obese individuals. Biomed Res Int 2015; 2015: 548734. https://doi.org/10.1155/2015/548734.

17. Andrade-Oliveira V, Câmara NOS, Moraes-Vieira PM. Adipokines as drug targets in diabetes and underlying disturbances. J Diabetes Res 2015; 2015: 681612. https://doi.org/10.1155/2015/681612.

18. Jeppesen J, Hansen TW, Olsen MH, Rasmussen S, Ibsen H, TorpPedersen $\mathrm{Ch}$, et al. C-reactive protein, insulin resistance and risk of cardiovascular disease: a population-based study. Eur J Cardiovasc Prev Rehabil 2008; 15(5): 594-598. https://doi.org/10.1097/hjr.0b013e328308bb8b.

19. Mauer J, Denson JL, Brüning JC. Versatile functions for IL-6 in metabolism and cancer. Trends Immunol 2015; 36(2): 92-101. https://doi.org/10.1016/j.it.2014.12.008

20. Fasshauer $M$, Blüher $M$. Adipokines in health and disease. Trends Pharmacol Sci 2015; 36(7): https://doi.org/10.1016/j.tips.2015.04.014.

21. Berstein LM, Poroshina TE, Vasilyev DA. Adipokines, myokines and cytokines in endometrial cancer patients: relations to obesity phenotype of excessive body mass and features of the tumor. Obesity and metabolism 2017; 14(1): 35-40. Russian. https://doi.org/10.14341/omet2017135-40.
22. Mariani F, Roncucci L. Chemerin/chemR23 axis in inflammation onset and resolution. Inflamm Res 2015; 64(2): 85-95. https://doi.org/10.1007/s00011-014-0792-7.

23. Phillips CM, Dillon Ch, Harrington JM, McCarthy VJ, Kearney PM, Fitzgerald AP, et al. Defining metabolically healthy obesity: role of dietary and lifestyle factors. PLoS One 2013; 8(10): e76188. https://doi.org/10.1371/journal.pone.0076188.

\section{Authors:}

Elena V. Ostrovskaya - MD, PhD Student, Department of Endocrinology №1, Institute of Clinical Medicine, I.M. Sechenov First Moscow State Medical University (Sechenov University), Moscow, Russia; https://orcid.org/0000-0001-5983-5350.

Tatiana I. Romantsova - MD, DSc, Professor, Department of Endocrinology №1, Institute of Clinical Medicine, I.M. Sechenov First Moscow State Medical University (Sechenov University), Moscow, Russia. ORCID: https://orcid.org/0000-0003-3870-6394.

Andrei N. Gerasimov - MD, DSc, Professor, Department of Medical Informatics and Statistics, Institute of Digital Medicine, I.M. Sechenov First Moscow State Medical University (Sechenov University), Moscow, Russia. ORCID: https://orcid.org/0000-0003-4549-7172.

Tamara E. Novoselova - Senior Lecturer, Department of Medical Informatics and Statistics, Institute of Digital Medicine, I.M. Sechenov First Moscow State Medical University (Sechenov University), Moscow, Russia. ORCID: https://orcid.org/0000-0002-6236-5668. 